\title{
Factors Influencing Urban Residents' Intention of Garbage Sorting in China: An Extended TPB by Integrating Expectancy Theory and Norm Activation Model
}

\author{
Huajie Wang $1,2,3{ }^{\infty}$, Herong Gui ${ }^{2}$, Chong Ren ${ }^{4}$ and Guijian Liu ${ }^{3, *}$ \\ 1 Department of Environmental Science and Engineering, College of Life Science, Huaibei Normal University, \\ Huaibei 235000, China; wanghj@chnu.edu.cn \\ 2 National Engineering Research Center of Coal Mine Water Hazard Controlling, Suzhou University, \\ Suzhou 234000, China; guiherong@163.com \\ 3 CAS Key Laboratory of Crust-Mantle Materials and the Environments, School of Earth and Space Sciences, \\ University of Science and Technology of China, Hefei 230026, China \\ 4 School of Public Affairs, University of Science and Technology of China, Hefei 230026, China; \\ renchong@ustc.edu.cn \\ * Correspondence: lgj@ustc.edu.cn
}

Citation: Wang, H.; Gui, H.; Ren, C.; Liu, G. Factors Influencing Urban Residents' Intention of Garbage Sorting in China: An Extended TPB by Integrating Expectancy Theory and Norm Activation Model. Sustainability 2021, 13, 12985. https://doi.org/10.3390/su132312985

Academic Editors: Anna Visvizi, Wadee Alhalabi, Shahira Assem Abdel Razek, Paolo Gerli and Orlando Troisi

Received: 24 September 2021 Accepted: 22 November 2021 Published: 24 November 2021

Publisher's Note: MDPI stays neutral with regard to jurisdictional claims in published maps and institutional affiliations.

Copyright: (c) 2021 by the authors. Licensee MDPI, Basel, Switzerland. This article is an open access article distributed under the terms and conditions of the Creative Commons Attribution (CC BY) license (https:// creativecommons.org/licenses/by/ $4.0 /)$.

\begin{abstract}
With the deepening of the garbage classification policy strength, making urban household garbage sorting mandatory in China, it is imperative to clarify the key factors affecting the urban residents' intention to behave in garbage classification. Though it has attracted the attention of researchers, there are still several aspects that need to be supplemented and improved. Thus, this study aims to investigate the critical factors affecting the urban residents' intention of garbage sorting and develop an extended model of planned behavior by integrating expectancy theory (ET) and norm activation model (NAM). Given the positive externalities of urban residents' garbage sorting behaviors, awareness of consequences and attribution of responsibility are correspondingly interpreted as environmental benefits (EB) and environmental concerns (EC). The sample data of 668 urban residents who lived in four pilot cities of garbage classification in China were collected and adopted to the structural equation modeling (SEM) with bootstrapping estimation method to assess the causal relationship between variables. The results indicated that the expectation (Exp) was a significant positive predictor of garbage sorting intention. Attitude (AT), perceived behavior control (PBC) and subjective norm (SN) positively affected urban residents' expectation of garbage sorting, with SN having the most significant direct impact. The results also found that the EB has significant influences EC, which strongly influences urban residents' expectation of garbage sorting. Furthermore, the total effect of EC on Exp is higher than other paths, and the mediating effect of SN on Exp by AT and PBC is greater than other indirect paths, which accounted for about $27.1 \%$ of the total effect. Finally, we discuss both theoretical and practical implications, along with recommendations for future research.
\end{abstract}

Keywords: garbage classification intention; theory of planned behavior; expectancy theory; environmental benefits; environmental concerns

\section{Introduction}

The increasing population size and sustained economic growth have resulted in annual increases in domestic garbage in China. Based on the China Statistical Yearbook, during the 13th Five-Year Plan period, the amount of China's domestic garbage has risen from 204 million tons in 2016 to 242 million tons in 2019, with an average annual growth rate of about $6 \%$. This amount is expected to exceed 270 million tons by 2021. Current disposal methods include mixed landfill (about 45.59\% in 2019) and mixed incineration (approximately 50.69\% in 2019), intensifying the demand for landfill land and greenhouse gas emissions during incineration. These problems will ultimately lead to tension in the 
human-environment relationship and a significant increase in environmental pollution [1]. Garbage has been referred to as an "urban mineral", a concept that has been validated in the literature $[2,3]$.

In March 2017, the National Development and Reform Commission of the People's Republic of China and the Ministry of Housing and Urban-Rural Development of the People's Republic of China jointly issued The Implementation Plan for the Household Garbage Classification System, marking urban household garbage sorting mandatory in China. In June 2019, the Notice on the Comprehensive Implementation of Domestic Waste Classification in Cities at the Prefectural Level and Above was issued by the Ministry of Housing and UrbanRural Development of the People's Republic of China. In the start-up and pilot phases, garbage classification and processing systems will be established in 46 key cities at the prefectural level and above. In 2020, the second revision of the Law of the People's Republic of China on the Prevention and Control of Environmental Pollution by Solid Waste was completed, and garbage classification was upgraded to an independent section, which is an integral part of the law. Therefore, the garbage classification policy has been refined, and the implementation regulations are more specific, making garbage sorting in urban households mandatory. The subsequent promulgation and formulation of policies and systems at the macro level promote top-level design and the formation of a system for garbage classification. Therefore, the degree of participation of urban residents in garbage classification determines the practical operation and long-term success of policies and systems. Previous studies found that the results of urban residents' garbage sorting were unsatisfactory, and variable results were observed for different cities [1,4-6]. Thus, it is imperative to identify the main influencing factors affecting urban residents' behavioral intention of garbage sorting.

Few studies have focused on urban residents' behavioral intention of garbage sorting and the influencing factors. However, several aspects need to be discussed. First, due to the popularity of the policy of mandatory garbage classification, the logical relationship between the main predictive variables affecting urban residents' behavioral intention/behavior may need to be adjusted. Several studies have shown that urban residents' intention and behavior of garbage sorting were always positively related. However, the causal relationship between the determinants and the intention is not consistent. Zhang et al. [7] found that the attitude (AT), perceived behavioral control (PBC) and classification knowledge (CK) were positively related to Chengdu residents' intention of garbage sorting, and the attitude had the most significant impact. However, the subjective norm (SN) and infrastructure had no significant effect on intention, and incentive measures failed to strengthen the intent.

In contrast, Wang et al. [8] showed that attitude, subjective norm, perceived behavioral control, moral norm and classification knowledge about garbage sorting positively affected Heifei residents' intention, and the classification knowledge had the most significant impact. Meanwhile, incentive measures strengthened the relationship between intention and behavior. In addition, Zhang et al. [9] found that attitude had the greatest impact on Tai'an residents' intention of garbage sorting. However, the subjective norm and perceived behavioral control had no significant effect on the residents' intention, and facility accessibility failed to moderate the relationship between intention and behavior. Wang et al. [10] analyzed the antecedent variables of garbage sorting intention using the extended theory of planned behavior (TPB). The results showed that the residents' garbage sorting intentions were significantly correlated with the behavior, facility accessibility and moral norm. In contrast, the perceived behavioral control and policy factors did not significantly affect residents' garbage sorting intention. The second aspect that requires additional research is that differences in the results of existing studies may imply that additional variables need to be integrated to strengthen the relationship between the independent and dependent variables based on the TPB framework. The reviewed literature indicates that the relationship between subjective norm, perceived behavioral control and classification intention is uncertain. Incentive measures and facility accessibility do not 
always strengthen the relationship between behavioral intentions and behavior. Therefore, the extended model TPB adjusts the relationship between variables to provide a better explanation of the residents' intention to sorting. Third, more comprehensive information can be obtained by increasing the number of survey regions. The homogeneity of residents from a single region may affect the results due to similarities in the knowledge structure, subjective norm and attitude.

It is undeniable that the extended TPB model has higher robustness for interpreting and predicting behavioral intentions by integrating other variables. Therefore, in this study, the extension of the TPB model is based on the following two aspects. First, we utilize Vroom's expectancy theory (ET) since the expectation (Exp) is an essential source of driving an individuals' behavioral intention. Second, we incorporate the norm activation model (NAM) because moral norm are critical predictors of an individual's positive attitude. In addition, the awareness of consequences (ACs) and attribution of responsibility are correspondingly interpreted as environmental benefits (EB) and environmental concerns (EC) and as antecedent variables of subjective norm (SN) and moral norm (MN), respectively. The objectives of this research are to:

(1) Use Vroom's expectancy theory (ET) to examine the effect of individual's expectation (Exp) on urban residents' intention to garbage sorting.

(2) Use the NAM to analyze the effect of environmental benefits and concerns on subjective norms and moral norms, respectively.

(3) Assess the mediating effect of environmental concerns on expectation (EC $\rightarrow$ Exp) relationship based on the attitude, moral norm and perceived behavioral control and the mediating effect of subjective norm on expectation ( $\mathrm{SN} \rightarrow \operatorname{Exp}$ ) relationship base on the attitude and perceived behavioral control.

Thus, this paper provides significant information for researchers and decisionmakers to understand urban residents' intention to garbage sorting and develop suitable plans to guide garbage classification using a science-based method.

The remainder of this paper is organized as follows: Section 2 explains the conceptual framework and hypothesis. Section 3 presents the methodology, including the measurements, sample collection and profile and data analysis. Section 4 describes the results, including the analyses of the model and the mediating effects. Section 5 discusses the results from theoretical and practical aspects. The final section provides the conclusion.

\section{Conceptual Framework and Hypothesis}

\subsection{Theory of Planned Behavior and Its Extended Model}

The theory of reasoned action (TRA) and the TPB have been widely used in a multitude of behavioral domains to explain an individual's behavioral intention and behavior in the decision-making process [11-17]. The TRA model holds that subjective norm and attitude toward behavior are the driving factors affecting behavioral intention [18]. Subsequently, Ajzen [19] incorporated perceived behavioral control into the TRA model, substantially improving the predictive ability of this model and extending the TPB. A favorable attitude, supportive subjective norm and sufficiently strong perceived behavioral control are the determinants of an optimistic behavioral intention. Behavioral intention results in behavior, and perceived behavioral control affects this behavior [20-22]. Intention reflects the degree of effort to implement a particular behavior and can also be understood as the individual's subjective possibility or intention to behave in a specific manner in the future [19]. Some empirical studies have confirmed that intention is a significant indicator of actual behavior; thus, it is feasible for intention to replace real action as a dependent variable [15,23-26].

Since garbage sorting by urban residents falls into the pro-environmental domain, it is reasonable for this study to use the TPB model as the basic framework. Nevertheless, as Ajzen [22] said, "the TPB is, in principle, open to the inclusion of additional predictors". Therefore, additional variables are required to analyze individual behavior decisions in specific context. The criteria for adding variables to the TPB model are as follows [22]: 
(1) Compatibility. The added variables meet the criteria for defining and measuring specific behaviors in the same manner as the theory's existing variables.

(2) Causality. The added variables meet the criteria of being causal factors that determine intention or behavior.

(3) Independence. The added variables should not be the same as the theory's existing variables.

(4) Versatility. The added variables are suitable for a multitude of behavioral domains.

\subsection{The Extended TPB Model Based on Expectation (Exp)}

The well-respected expectancy theory (ET) was proposed by Vroom [27] to explain the decision-making process of individuals who have various behavioral alternatives [28-32]. Traditionally, the framework states that an individual's desire for a performance target (defined as valence) increases their level of effort (defined as instrumentality) to achieve expected outcomes (defined as expectation), i.e., the higher the efforts, the higher the likelihood of achieving the performance target [31,32]. Vroom's expectancy theory emphasizes how to promote the formation of individual motivational forces, thus facilitating the creation of appropriate incentive plans in the workplace. The theory is also referred to as the process theory of motivation. The higher the individual's cognition of self-competence, the more likely they are to form the behavioral intention or implement the behavior. Researchers have found that individual expectation was the determinant of behavioral choice and had a significant positive effect on pro-environment behavioral intention [24,29]. In the current study context, the expectation factors of expectancy theory include knowledge, skills, confidence and being a role model for other people, denoting an individual's cognition of self-competence. These indicators are consistent with the internal factors of the perceived behavioral control proposed by Kraft et al. [33], reflecting the rationality of expectation as an additional construct based on the TPB. The following hypothesis is developed:

Hypothesis 1. (H1.) Expectation (Exp) significantly affects urban residents' intention to garbage sorting (Int).

Attitude (AT) as an accessible behavioral belief in the TPB model is based on a rational evaluation of an individual's behavioral intention/behavior. In performing a specific behavior, a favorable attitude can increase an individual's desire for knowledge, skills and confidence, resulting in expectation that generates behavioral intentions/behavior $[8,34,35]$. As a result, we believe that the urban residents' attitudes are positively associated with the expectation of garbage sorting.

Subjective norms (SN) refer to the social pressure that individuals perceive coming from important people around them (e.g., families, friends or neighbors, etc.) when making decisions about whether to perform an action or not. When a person believes that people around them support or affirm their behavior and have a positive attitude toward the behavior, positive perception expectations are formed, resulting in behavioral intention/behavior. Studies have found that subjective norm had the most significant effect or no effect among all antecedent variables $[7,16,23,36,37]$. The main reason for this difference lies in the cultural differences between countries, namely collectivism and individualism, whereas the effect from the actual behavior is minor. Previous studies have observed positive relationships between subjective norms, attitude and perceived behavioral control [38-40]. Therefore, subjective norms are crucial to the attitudes, perceived behavioral control and expectation of urban residents' regarding garbage sorting.

Perceived behavioral control (PBC) is regarded as the degree of perceived difficulty to enact a behavior according to one's abilities or experiences. It reflects the individual's perceived ability to overcome barriers to perform a behavior [22]. In addition, Kraft, Rise, Sutton and Røysamb [33] proposed that perceived behavioral control includes both internal and external perception factors. Internal factors mainly refer to skills, knowledge, information identification and confidence, whereas external perception factors include time, 
energy, cost and other aspects. In this study, the internal factors of perceived behavioral control are equivalent to the expectation factors of the expectancy theory. Typically, direct or indirect effects impact the perceived behavioral control in the relationship with intention, and indirect effects account for about $20 \%$ to $60 \%$ of the total effects [23,41,42].

In view of this, the following hypotheses are proposed:

Hypothesis 2. (H2.) Attitude (AT) positively affects urban residents' expectation of garbage $\operatorname{sorting}(\operatorname{Exp})$.

Hypothesis 3. (H3.) Subjective norms (SN) positively affect urban residents' expectation of garbage sorting (Exp).

Hypothesis 4. (H4.) Perceived behavioral control (PBC) positively affects urban residents' expectation of garbage sorting (Exp).

Hypothesis 5. (H5.) Subjective norm (SN) positively affects urban residents' attitude of garbage sorting $(A T)$.

Hypothesis 6. (H6.) Subjective norms (SN) positively affect urban residents' perceived behavioral control (PBC) of garbage sorting.

\subsection{The Extended TPB Model Based on Environmental Benefit (EB) and Environmental Concerns (EC)}

The decision-making process of an individual is driven by multiple motivations and is not necessarily caused only by a rational person's assumptions. Therefore, the urban residents' garbage-sorting behavior is regarded as a mixture of self-interest and altruism. Norm activation theory (NAM), which aims to provide a reasonable explanation for prosocial intentions/behaviors, states that people exhibit altruism and helpfulness in daily life $[43,44]$. Studies have reported that supportive moral norm will lead to an individual's favorable attitude toward forming intentions and enacting a behavior $[23,45,46]$. Thus, the decision-making process of urban residents' for sorting garbage falls into the moral domain and is defined as moral norm (MN) in this study. Awareness of consequence is another variable in the NAM model. It indicates that environmental quality is directly related to population health, social development and the natural environment [47]. Not performing a pro-social behavior will have adverse awareness consequences [11]. Similarly, individuals are more inclined to be aware of positive consequences by participating in garbage sorting. Thus, awareness of consequence is the antecedent variable for subjective and moral norms since they improve the environmental quality, promote resource recovery and reduce human health risks. The awareness of positive consequences leading to environmental well-being is an environmental benefit (EB). Cudjoe, Yuan and Han [6] utilized the TRA and found a positive relationship between residents' awareness of environmental benefit (EB) and their garbage sorting intention. Therefore, environmental benefits of garbage sorting may be positively related to an individual's subjective and moral norm.

The attribution of responsibility is the last variable in the NAM framework. It refers to individual behavior that can prevent or aggravate potential adverse consequences [48] of not performing a pro-socially behavior [11]. Likewise, individuals are more inclined to take responsibility for positive consequences by participating in garbage sorting, thus enhancing the individuals' perceived behavioral control and moral norm, which is conducive to environmental protection, the balance of nature and humans living in harmony with the environment $[49,50]$. Environmental concern (EC), which refers to an individual's concern level regarding environmental issues, is a valid predictor of environmentally conscious behavior [51]. We established the following hypotheses:

Hypothesis 7. (H7.) Moral norm (MN) significantly influences urban residents' attitude of garbage sorting $(A T)$. 
Hypothesis 8. (H8.) Environmental benefits (EB) significantly influence urban residents' subjective norm (SN).

Hypothesis 9. (H9.) Environmental benefits (EB) significantly influence urban residents' moral norm $(M N)$.

Hypothesis 10. (H10.) Environmental concerns (EC) significantly influence urban residents' perceived behavioral control (PBC).

Hypothesis 11. (H11.) Environmental concerns (EC) significantly influence urban residents' moral norm (MN).

Therefore, the proposed conceptual model of the hypothesis is shown in Figure 1.

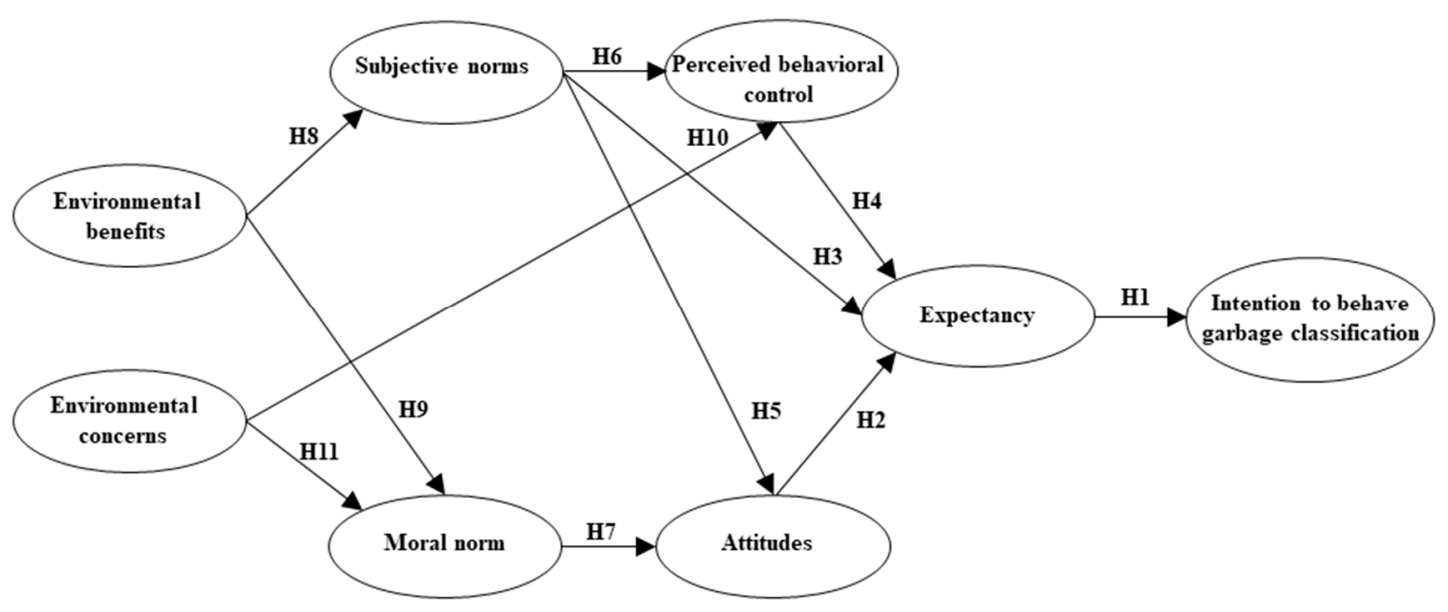

Figure 1. The conceptual model framework of hypothesis.

\section{Methodology}

\subsection{Questionnaire Design}

The measurement scale was developed based on the proposed conceptual model (Figure 1), which included 37 measurement items from previous literature (see Table S1 for details) $[11,28,52-58]$. These observed variables were appropriate amendments developed to fit this study's settings. Then, we improved the precision of the measurement from the following three aspects. First, the linguistic description of each observation variable was consistent with the background of garbage classification in China. Second was a pre-test and reviews by professors, experts and urban residents from the pilot city of garbage classification. According to their opinions and suggestions, each item was improved to be best read and understood. Third, this study conducted a pilot with 30 participants as samples to guarantee content validity. The questionnaire adopted a 5-point Likert scale (from $1=$ strongly disagree/extremely unimportant to $5=$ strongly agree/extremely important).

\subsection{Data Collection}

Questionnaires were conducted in four pilot cities in the eastern region (Beijing and Shanghai), the central region (Hefei) and the southwest region (Chongqing) of China. These cities were identified as urban garbage classification pilot cities by the Chinese government. The urban residents' intention to garbage sorting in these cities would represent of citizens in other Chinese cities facing similar problems. To make respondents more aware of a policy document issued by the Ministry of Housing and Urban-Rural Development of the People's Republic of China, essential background information about the Notice on the Comprehensive Implementation of Domestic Waste Classification in Cities at the Prefectural Level and Above (in 
June 2019) was introduced to respondents in the first part of the questionnaire, namely by the three-step strategy: In the start-up and pilot phases (from 2019 to 2020), garbage classification and processing system would be established in the 46 pilot cities. From 2021 to 2022, at least one district of each prefecture-level city is been fully covered by domestic garbage classification, and a street of the rest districts is set up as a demonstration site for domestic garbage classification; by 2025, a garbage classification system will be built in China. The survey was conducted from January to March of 2021. The questionnaire survey was conducted using an online. The invitation cards with the URL of the questionnaire web page were sent to a residential property in the target cities (http:/ /www.sojump.com, accessed on 18 March 2021). After the completion, small incentives (i.e., red envelopes) were randomly assigned to the participants to appreciate their contribution. Adopting a convenience sampling method, questionnaires were distributed among urban residents, mostly young people. Previous studies have confirmed that samples of young people were reliable by the convenience sampling method $[59,60]$. About $80 \%$ of responses were from young people aged below 45 years old in this study. A total of 1000 invitation cards were sent out, and 758 online replies were received. Ninety questionnaires were removed based on logic errors and the same options. Ultimately, 668 valid responses were received, for a response rate of $66.8 \%$.

One-factor analysis of variance (ANOVA) was used to check significant differences between the four pilot cities. No significant difference was found in all the constructs among the four pilot cities $(p<0.05)$. Thus, it was feasible to combine the samples of the four pilot cities into a complete sample for data analysis. The chi-square test showed no problem in the non-response bias assessment of the data $(p>0.05)$. Common Method Bias (CMB) might have influenced the observed strength among the study variables [61]. On the one hand, $\mathrm{CMB}$ might have mitigated by collecting data from multiple sources [62]. As can be seen from the occupational distribution of the sample, the different sources mainly include self-employment, corporate employees and civil servants/public institution staff. On the other hand, Harman's one-factor method was employed to check the CMB. Firstly, exploratory factor analysis found that the variance interpretation rate of the first factor was only $9.965 \%$ (less than $50 \%$ ) before no rotation. The results indicated that the CMB was acceptable. Moreover, the maximum correlation coefficient of all variables in the scale is 0.427 (less than 0.9), which also indicates that the CMB of the data is not a problem.

\subsection{Data Analysis Method}

Statistical analysis and structural equation modeling (SEM) employed SPSS 25.0 and AMOS 24.0. SEM calculated the simultaneous assessment of the general relationships between various independent and dependent variables [63-65]. We followed Anderson and Gerbing [66] recommendations to employ a two-step process in the current study. Accordingly, we first performed confirmatory factor analysis (CFA). Following a satisfactory fitting result, the structural model was further evaluated. The path coefficients of each hypothetical relationship were measured, and the extent of model fit was often focused on these indices such as CFI, TLI, RMSEA and so on.

\section{Data Analysis and Results}

\subsection{Sample Profile}

The survey was conducted in four pilot cities in China, whose population accounts for $6.25 \%$ of the total population. Based on the results of China's 7 th National Population Census, $17.9 \%$ of people are aged $0-14,63.4 \%$ are aged $15-59$, and $18.7 \%$ are aged 60 and above. A total of $51.2 \%$ of residents were male. These percentages were consistent with those listed in Table 1. As can be seen from Table 1, 52.5\% of responses were male. About $79 \%$ of the respondents were aged 26-45. Most respondents had an educational level of bachelor's degree or higher (66\%), and only $16.3 \%$ had a senior high school education or below. In comparison, the average education level in literature [7-9,12,15,23,67] was: $21.4 \%$ senior high school or below, $24.7 \%$ junior college, $34.5 \%$ bachelor's degree, $21.6 \%$ master's 
degree or Ph.D., which is similar to the survey result of this study. The respondents included self-employed people, corporate employees and civil servants/public institution staff, accounting for $18 \%, 32.6 \%$ and $46.4 \%$, respectively. The monthly income level was predominantly RMB 5001 to 10,000 , accounting for about $35 \%$ of the total sample.

Table 1. The demographic composition of the samples $(\mathrm{N}=668)$.

\begin{tabular}{|c|c|c|c|c|c|c|c|}
\hline Variable & Category & Frequency & $\begin{array}{l}\text { Percent } \\
\quad(\%)\end{array}$ & Variable & Category & Frequency & $\begin{array}{c}\text { Percent } \\
(\%)\end{array}$ \\
\hline \multirow[t]{2}{*}{ Gender } & Male & 351 & 52.5 & & $\begin{array}{l}\text { Master's degree or } \\
\text { Ph.D. }\end{array}$ & 172 & 25.7 \\
\hline & Female & 317 & 47.5 & \multirow{4}{*}{ Occupational } & Self-employment & 120 & 18.0 \\
\hline \multirow{5}{*}{ Age } & Under 25 & 11 & 1.6 & & $\begin{array}{l}\text { Corporate } \\
\text { employees }\end{array}$ & 217 & 32.6 \\
\hline & $26-35$ & 224 & 33.5 & & $\begin{array}{c}\text { Civil } \\
\text { servants/Public } \\
\text { Institution staff }\end{array}$ & 309 & 46.4 \\
\hline & $36-45$ & 300 & 44.9 & & Retirees & 20 & 3.0 \\
\hline & $46-55$ & 112 & 16.8 & \multirow{5}{*}{$\begin{array}{l}\text { Income/month } \\
(\mathrm{RMB})\end{array}$} & Under 3000 & 54 & 8.1 \\
\hline & Over 56 & 21 & 3.1 & & $3001-5000$ & 131 & 19.6 \\
\hline \multirow{3}{*}{$\begin{array}{l}\text { Educational } \\
\text { level }\end{array}$} & $\begin{array}{l}\text { Senior high school } \\
\text { or below }\end{array}$ & 109 & 16.3 & & $5001-10,000$ & 231 & 34.6 \\
\hline & Junior college & 124 & 18.6 & & $10,001-15,000$ & 104 & 15.6 \\
\hline & Bachelor's degree & 263 & 39.4 & & Over 15,000 & 148 & 22.2 \\
\hline
\end{tabular}

\subsection{Establishment of the Model and Measurements}

Before the confirmatory factor analysis (CFA), the skewness and kurtosis of each variable were examined (skewness $=-0.099$ to 0.458 and kurtosis $=-0.775$ to 0.448 ), and their absolute values were all within 1 . Therefore, the sample data met the normal distribution assumption. CFA was used to check the reliability and validity of each construct using the maximum likelihood [24,68]. A satisfactory fitting result was obtained with the following parameters: chi-square/degree of freedom $=1.907$, RMSEA $=0.037$, CFI $=0.952, \mathrm{TLI}=0.946, \mathrm{IFI}=0.953, \mathrm{SRMR}=0.059$.

As shown in Table 2, the lowest values of Cronbach's alpha and the composite reliability were 0.773 and 0.832 , respectively; both values were above the recommended benchmark value of $0.70[69,70]$, thus confirming the consistency and reliability. The loadings of all observed variables were within 0.703-0.913 (Table 2), and all were higher than the standard value of $0.70[15,71,72]$. The average variance extracted (AVE) was in the range of $0.555-0.669$, which exceeded 0.5 , thus supporting convergent validity. Table 3 shows that the minimum value of $\sqrt{ } \mathrm{AVE}$ was 0.745 among the latent constructs, the maximum value of the correlation coefficient between two different latent constructs was 0.427 and ASV $<$ AVE, thus also supporting discriminant validity $[15,69]$. These results indicate that the proposed model has adequate reliability and good validity.

Table 2. Results of reliability and validity analysis.

\begin{tabular}{ccccc}
\hline Construct and Measurement Items & Loadings & Cronbach's Alpha & CR & AVE \\
\hline Environmental concerns (EC) & & & & \\
EC1 & 0.767 & & & \\
EC2 & 0.743 & & 0.902 & 0.669 \\
EC3 & 0.764 & & \\
EC4 & 0.913 & & \\
EC5 & 0.888 & & \\
\hline
\end{tabular}


Table 2. Cont.

\begin{tabular}{|c|c|c|c|c|}
\hline Construct and Measurement Items & Loadings & Cronbach's Alpha & CR & AVE \\
\hline \multicolumn{5}{|l|}{ Moral norm (MN) } \\
\hline MN1 & 0.785 & \multirow{4}{*}{0.791} & \multirow{4}{*}{0.847} & \multirow{4}{*}{0.58} \\
\hline MN2 & 0.789 & & & \\
\hline MN3 & 0.744 & & & \\
\hline MN4 & 0.727 & & & \\
\hline \multicolumn{5}{|l|}{ Attitudes of garbage sorting (AT) } \\
\hline AT1 & 0.763 & \multirow{4}{*}{0.79} & \multirow{4}{*}{0.841} & \multirow{4}{*}{0.57} \\
\hline AT2 & 0.718 & & & \\
\hline AT3 & 0.796 & & & \\
\hline AT4 & 0.743 & & & \\
\hline \multicolumn{5}{|l|}{ Environmental benefits (EB) } \\
\hline EB1 & 0.755 & \multirow{5}{*}{0.833} & \multirow{5}{*}{0.866} & \multirow{5}{*}{0.563} \\
\hline EB2 & 0.747 & & & \\
\hline EB3 & 0.799 & & & \\
\hline EB4 & 0.723 & & & \\
\hline EB5 & 0.725 & & & \\
\hline \multicolumn{5}{|l|}{ Subjective norm (SN) } \\
\hline SN1 & 0.799 & \multirow{4}{*}{0.773} & \multirow{4}{*}{0.832} & \multirow{4}{*}{0.555} \\
\hline SN2 & 0.710 & & & \\
\hline SN3 & 0.718 & & & \\
\hline SN4 & 0.748 & & & \\
\hline \multicolumn{5}{|l|}{ Perceived behavioral control (PBC) } \\
\hline PBC1 & 0.707 & \multirow{4}{*}{0.791} & \multirow{4}{*}{0.839} & \multirow{4}{*}{0.567} \\
\hline PBC2 & 0.784 & & & \\
\hline PBC3 & 0.785 & & & \\
\hline PBC4 & 0.733 & & & \\
\hline \multicolumn{5}{|l|}{ Expectation of garbage sorting (Exp) } \\
\hline Exp1 & 0.791 & \multirow{4}{*}{0.854} & \multirow{4}{*}{0.86} & \multirow{4}{*}{0.606} \\
\hline Exp2 & 0.749 & & & \\
\hline Exp3 & 0.804 & & & \\
\hline Exp4 & 0.768 & & & \\
\hline \multicolumn{5}{|l|}{ Intention to garbage sorting (Int) } \\
\hline Int1 & 0.703 & \multirow{7}{*}{0.840} & \multirow{7}{*}{0.918} & \\
\hline Int2 & 0.814 & & & \\
\hline Int3 & 0.796 & & & \\
\hline Int4 & 0.758 & & & 0.616 \\
\hline Int5 & 0.793 & & & \\
\hline Int6 & 0.819 & & & \\
\hline Int7 & 0.806 & & & \\
\hline
\end{tabular}

Table 3. Descriptive statistics, convergent and discriminant validity.

\begin{tabular}{cccccccccc}
\hline Construct & EC & MN & AT & EB & SN & PBC & Exp & Int & ASV \\
\hline EC & 0.818 & 0.114 & 0.117 & 0.077 & 0.099 & 0.065 & 0.139 & 0.136 \\
MN & $0.337^{* * *}$ & 0.762 & 0.128 & 0.061 & 0.061 & 0.066 & 0.099 & 0.076 \\
AT & $0.341^{* * *}$ & $0.357^{* * *}$ & 0.755 & 0.057 & 0.063 & 0.048 & 0.096 & 0.083 & 0.1086 \\
EB & $0.277^{* *}$ & $0.247^{* *}$ & $0.239^{* * *}$ & 0.751 & 0.136 & 0.183 & 0.109 & 0.122 \\
SN & $0.315^{* * *}$ & $0.246^{* *}$ & $0.250^{* * *}$ & $0.369^{* * *}$ & 0.745 & 0.122 & 0.096 & 0.115 & 0.106 \\
PBC & $0.255^{* * *}$ & $0.257^{* * *}$ & $0.220^{* * *}$ & $0.428^{* * *}$ & $0.349^{* * *}$ & 0.753 & 0.130 & 0.126 \\
Exp & $0.373^{* * *}$ & $0.314^{* * *}$ & $0.310^{* * *}$ & $0.329^{* * *}$ & $0.310^{* * *}$ & $0.361^{* * *}$ & 0.778 & 0.183 \\
Int & $0.369^{* * *}$ & $0.276^{* * *}$ & $0.288^{* * *}$ & $0.349^{* * *}$ & $0.339^{* * *}$ & $0.355^{* * *}$ & $0.427^{* * *}$ & 0.785 & 0.122 \\
\hline
\end{tabular}

Note: The numbers in the diagonal row (bold) are the values of $\sqrt{\mathrm{AVE}}$; The numbers above diagonal are the squared correlation coefficients between the constructs; the numbers below the diagonal are the correlation coefficients between the constructs. ASV is Average Shared Variance; ${ }^{* *} p<0.01,{ }^{* * *} p<0.001$. 


\subsection{Structural Model Analysis}

AMOS 24.0 was used to analyze the hypothesis model. The model fit showed a satisfactory goodness-of-fit (chi-square / degree of freedom $=2.235$, RMSEA $=0.043, \mathrm{CFI}=0.933$, $\mathrm{TLI}=0.927, \mathrm{IFI}=0.934)$ [72]. The results indicated a good fit of the hypothesis model. The path coefficients obtained from the AMOS results are listed in Table 4. The results supported all the hypothetical paths, and the modification indices suggested potential improvements to the hypothesis model. After adding two newly discovered paths from environmental concerns to expectation (D1) and environmental benefits to environmental concerns (D2), the goodness-of-fit improved significantly. The results of the final model fit were as follows: chi-square $/$ degree of freedom $=2.112, \mathrm{RMSEA}=0.041, \mathrm{CFI}=0.940, \mathrm{TLI}=0.934, \mathrm{IFI}=0.940$, $\mathrm{SRMR}=0.076$. A comparison of the fit index results between the final model and the original TPB model (chi-square $/$ degree of freedom $=2.294$, RMSEA $=0.044, \mathrm{CFI}=0.949, \mathrm{TLI}=0.941$, IFI $=0.949)$ confirmed that the final model was reasonable $(\triangle \mathrm{RMSEA}=0.003<0.015$ and $\Delta \mathrm{CFI}=0.009<0.01$ ) [73]. Therefore, the final model includes two new significant paths (D1 and D2); all paths are summarized in Table 4.

Table 4. Summary of hypotheses testing results.

\begin{tabular}{cccc}
\hline Path & Path Coefficient & t-Value & Results \\
\hline H1: Exp $\rightarrow$ Int & 0.564 & $9.895^{* * *}$ & Supported \\
H2: $\mathrm{AT} \rightarrow$ Exp & 0.190 & $2.836^{* * *}$ & Supported \\
H3: $\mathrm{SN} \rightarrow$ Exp & 0.205 & $4.271^{* * *}$ & Supported \\
H4: $\mathrm{PBC} \rightarrow$ Exp & 0.156 & $3.000^{* *}$ & Supported \\
H5: $\mathrm{SN} \rightarrow \mathrm{AT}$ & 0.178 & $7.417^{* * *}$ & Supported \\
$\mathrm{H} 6: \mathrm{SN} \rightarrow \mathrm{PBC}$ & 0.349 & $7.271^{* * *}$ & Supported \\
$\mathrm{H} 7: \mathrm{MN} \rightarrow \mathrm{AT}$ & 0.232 & $8.593^{* * *}$ & Supported \\
$\mathrm{H} 8: \mathrm{EB} \rightarrow \mathrm{SN}$ & 0.303 & $6.733^{* * *}$ & Supported \\
$\mathrm{H} 9: \mathrm{EB} \rightarrow \mathrm{MN}$ & 0.172 & $4.300^{* * *}$ & Supported \\
$\mathrm{H} 10: \mathrm{EC} \rightarrow \mathrm{PBC}$ & 0.132 & $3.882^{* * *}$ & Supported \\
$\mathrm{H} 11: \mathrm{EC} \rightarrow \mathrm{MN}$ & 0.245 & $7.000^{* * *}$ & Supported \\
$\mathrm{D} 1: \mathrm{EC} \rightarrow$ Exp & 0.316 & $9.294^{* * *}$ & Supported \\
$\mathrm{D} 2: \mathrm{EB} \rightarrow$ EC & 0.227 & $4.830^{* * *}$ & Supported \\
\hline
\end{tabular}

Note: ${ }^{* *} p<0.01,{ }^{* * *} p<0.001$.

We found that H1 (Exp $\rightarrow$ Int) had the highest path coefficient (See Table 4). The expectation of garbage sorting was a significant positive predictor of garbage sorting behavioral intention $\left(\beta=0.564, \mathrm{t}=9.895^{* *}\right)$. D1 $(\mathrm{EC} \rightarrow \mathrm{Exp})$ posited that the environmental concerns positively influenced expectation of garbage sorting, which was confirmed ( $\beta=0.316$, $t=9.294^{* *}$. These results indicate that the higher the environmental concern regarding garbage sorting, the higher the personal expectation is, and the more likely it is that the person will perform garbage sorting. Second, personal expectations were positively influenced by attitude $(\mathrm{H} 2)$, subjective norm $(\mathrm{H} 3)$ and perceived behavioral control $(\mathrm{H} 4)$. The links were all significant $\left(\beta \mathrm{H} 2=0.190, \mathrm{t}=2.836^{* *} ; \beta \mathrm{H} 3=0.205, \mathrm{t}=4.271^{* *} ; \beta \mathrm{H} 4=0.156\right.$, $\left.\mathrm{t}=3.000^{* *}\right)$, thus confirming $\mathrm{H} 2, \mathrm{H} 3$ and $\mathrm{H} 4$. In addition, the remaining path coefficients were H6 $\left(\beta=0.349, \mathrm{t}=7.271^{* * *}\right), \mathrm{H} 8\left(\beta=0.303, \mathrm{t}=6.733^{* * *}\right), \mathrm{H} 11\left(\beta=0.245, \mathrm{t}=7.000^{* * *}\right)$, H7 $\left(\beta=0.232, \mathrm{t}=8.593^{* * *}\right), \mathrm{D} 2\left(\beta=0.227, \mathrm{t}=4.830^{* * *}\right), \mathrm{H} 9\left(\beta=0.172, \mathrm{t}=4.300^{* * *}\right), \mathrm{H} 5$ $\left(\beta=0.178, \mathrm{t}=7.417^{* * *}\right)$ and $\mathrm{H} 10\left(\beta=0.132, \mathrm{t}=3.882^{* *}\right)$, and all links were significant. The effect of the subjective norm on perceived behavioral control was more dominant than the effect of environmental concern. The environmental concern had a more dominant influence on moral norm than environmental benefit, and the moral norm had a larger effect on attitude than subjective norm.

In the original TPB model, the path coefficients were $0.178(\mathrm{SN} \rightarrow \mathrm{AT}), 0.355(\mathrm{SN} \rightarrow \mathrm{PBC})$, $0.216(\mathrm{MN} \rightarrow \mathrm{AT}), 0.126(\mathrm{PBC} \rightarrow \mathrm{Int}), 0.106(\mathrm{SN} \rightarrow \mathrm{Int})$ and $0.196(\mathrm{AT} \rightarrow \mathrm{Int})$. In the hypothesis model, the path coefficients were $0.559(\operatorname{Exp} \rightarrow$ Int), 0.196 (AT $\rightarrow \operatorname{Exp}), 0.240(\mathrm{SN} \rightarrow \operatorname{Exp}), 0.200$ $(\mathrm{PBC} \rightarrow \operatorname{Exp}), 0.176(\mathrm{SN} \rightarrow \mathrm{AT}), 0.138(\mathrm{EC} \rightarrow \mathrm{PBC}), 0.346(\mathrm{SN} \rightarrow \mathrm{PBC}), 0.234(\mathrm{MN} \rightarrow \mathrm{AT}), 0.176$ $(\mathrm{EB} \rightarrow \mathrm{MN}), 0.298(\mathrm{~EB} \rightarrow \mathrm{SN})$ and $0.249(\mathrm{EC} \rightarrow \mathrm{MN})$. 


\subsection{Mediating Effect Analysis}

We used the bootstrapping method of MacKinnon et al. [74] and Williams and MacKinnon [75] to test the effect of the moderating variables. Unlike the Soble test, the bootstrap method does not assume a normal distribution of the indirect influence and does not require a large sample size [76,77]. In addition, no standard error is needed to estimate the interval of the mediating effect. If the $95 \%$ confidence interval does not contain zero $(95 \%$ C.I. $\not \subset 0$ ), the mediating effect holds. Therefore, the bootstrap method is more accurate and reliable for analyzing multiple mediating effects.

Table 5 presents the results of the direct, indirect and total effects analysis. The $95 \%$ confidence interval, positive asymptotic critical ratio (Z-values $>0$ ) and significant $p$-values of the test indicated that all mediating effects were positive and significant.

Table 5. The results of direct, indirect and total effects analysis.

\begin{tabular}{|c|c|c|c|c|c|c|c|}
\hline \multirow{2}{*}{ Effect Source } & \multirow{2}{*}{$\begin{array}{c}\text { Point } \\
\text { Estimate }\end{array}$} & \multicolumn{2}{|c|}{ Product of Coefficients } & \multicolumn{2}{|c|}{ Bias-Corrected $95 \%$ C.I. } & \multicolumn{2}{|c|}{ Percentile 95\% C.I. } \\
\hline & & SE & Z-Value & Lower & Upper & Lower & Upper \\
\hline Indirect Effects & & & & & & & \\
\hline $\mathrm{EC} \longrightarrow \mathrm{PBC} \longrightarrow \operatorname{Exp}(\mathrm{EE} 1)$ & 0.020 & 0.009 & $2.222 * * *$ & 0.006 & 0.044 & 0.005 & 0.042 \\
\hline$\underset{(\mathrm{EE} 2)}{\mathrm{EC} \longrightarrow \mathrm{MN} \longrightarrow \mathrm{AT} \longrightarrow \operatorname{Exp}}$ & 0.007 & 0.004 & $1.750 * *$ & 0.002 & 0.017 & 0.001 & 0.016 \\
\hline Total EE1 and EE2 & 0.028 & 0.010 & $2.800 * * *$ & 0.011 & 0.053 & 0.010 & 0.051 \\
\hline $\mathrm{SN} \longrightarrow \mathrm{AT} \longrightarrow \operatorname{Exp}(\mathrm{SE} 1)$ & 0.022 & 0.011 & $2.000 * *$ & 0.006 & 0.051 & 0.004 & 0.048 \\
\hline $\mathrm{SN} \longrightarrow \mathrm{PBC} \longrightarrow \operatorname{Exp}(\mathrm{SE} 2)$ & 0.054 & 0.019 & $2.842 * * *$ & 0.022 & 0.097 & 0.019 & 0.093 \\
\hline Total SE1 and SE2 & 0.076 & 0.022 & $3.455^{* * *}$ & 0.039 & 0.125 & 0.037 & 0.121 \\
\hline $\begin{aligned} \mathrm{EB} \longrightarrow & \mathrm{EC} \longrightarrow>\mathrm{MN}(\mathrm{EM} 1) \\
& \text { Direct Effects }\end{aligned}$ & 0.055 & 0.014 & $3.929^{* * *}$ & 0.032 & 0.087 & 0.030 & 0.084 \\
\hline $\mathrm{EC} \longrightarrow \operatorname{Exp}(\mathrm{EE})$ & 0.316 & 0.046 & $6.870^{* * *}$ & 0.220 & 0.405 & 0.222 & 0.406 \\
\hline $\mathrm{SN} \longrightarrow \operatorname{Exp}(\mathrm{SE})$ & 0.205 & 0.057 & $3.596^{* * *}$ & 0.089 & 0.314 & 0.091 & 0.315 \\
\hline $\begin{array}{l}\mathrm{EB} \longrightarrow \mathrm{MN}(\mathrm{EM}) \\
\text { Total Effects }\end{array}$ & 0.172 & 0.046 & $3.739 * * *$ & 0.084 & 0.261 & 0.085 & 0.263 \\
\hline Total EE and EE1 and EE2 & 0.344 & 0.045 & $7.644^{* * *}$ & 0.248 & 0.430 & 0.250 & 0.432 \\
\hline Total SE and SE1 and SE2 & 0.281 & 0.052 & $5.404^{* * *}$ & 0.173 & 0.379 & 0.175 & 0.379 \\
\hline $\begin{array}{c}\text { Total EM and EM1 } \\
\text { Contrasts }\end{array}$ & 0.228 & 0.045 & $5.067^{* * *}$ & 0.140 & 0.314 & 0.142 & 0.316 \\
\hline SE2 vs. EE1 & 0.034 & 0.016 & $2.125 * *$ & 0.011 & 0.075 & 0.008 & 0.068 \\
\hline
\end{tabular}

Note: 5000 bootstrap samples; ${ }^{* *} p<0.01,{ }^{* * *} p<0.001$.

The total indirect effects of the environmental concerns on expectation through attitude, moral norm and perceived behavioral control were positive and significant (Zvalue $=2.800>1.96,95 \%$ C.I. $\not \subset 0, p<0.001)$. Subsequently, we analyzed specific indirect effects of the EC $\rightarrow$ Exp relationship. As shown in Table 5, the specific indirect effects were EE1 0.020 (through the perceived behavioral control), EE2 0.007 (through the attitude and moral norm). After the examining the potential mediators, we found that the perceived behavioral control was a significant mediator of the EC $\rightarrow$ Exp relationship (Z-value $=2.222>1.96,95 \%$ C.I. $\not \subset 0, p<0.001)$, and the attitude and moral norm were mediators of the $\mathrm{EC} \rightarrow \operatorname{Exp}$ relationship $(Z$-value $=1.750,95 \%$ C.I. $\not \subset 0, p<0.01)$. Meanwhile, environmental concerns were also significant mediators of the $\mathrm{EB} \rightarrow \mathrm{MN}$ relationship (Z-value $=3.929>1.96,95 \%$ C.I. $\not \subset 0, p<0.001)$.

The $\mathrm{SN} \rightarrow$ Exp relationship was mediated by attitude and perceived behavioral control, and the total indirect impacts were positive and significant (Z-value $=3.455>1.96,95 \%$ C.I. $\not \subset 0, p<0.001$ ). Two specific indirect effects were SE1 0.020 (through attitude) and SE2 0.054 (through perceived behavioral control), and both attitude and perceived behavioral control were significant mediators of the $\mathrm{SN} \rightarrow$ Exp relationship, as shown in Table 5 . However, the difference between SE1 and SE2 was not significant (the data are not shown). The total indirect effect on expectation from subjective norm 0.076 (through attitude and perceived behavioral control), which was higher than that from environmental concerns 
0.028 (through perceived behavioral control, moral norm and attitude). The significant difference occurred due to the SE2 and EE1 (Z-value $=2.125>1.96,95 \%$ C.I. $\not \subset 0, p<0.01$ ). In contrast, the direct and total effects on expectation from environmental concerns were 0.316 and 0.344 , respectively (EE and Total EE and EE1 and EE2), which was greater than that from subjective norm (SE and Total SE and SE1 and SE2). The indirect effect of the subjective norm on expectation was $27.1 \%$ of the total effect.

\section{Discussion}

\subsection{Theoretical and Practical Implications}

This study investigated whether a mandatory garbage classification policy improved the intention of urban residents to sorting garbage in pilot cities and the influencing factors. The results are vital for follow-up policies and to determine the effectiveness of policy implementation. We established an extended TPB model that integrates the planned behavior, norm activation and expectation. The study provides new information on the relationship between expectation and intention of garbage sorting based on the extended TPB model. The integration deepens the current understanding of the expectation mechanism affecting garbage sorting and the resulting behavioral intent. Empirically, the study verified that the extended TPB model provided a valid framework for identifying the primary determinants influencing the intent of garbage sorting and the relationship between the determinants. Similar to previous studies, we added new variables into to improve the explanatory power of the extended TPB model $[15,16,49,71,78]$.

The empirical results of our study showed that expectation of garbage sorting as an antecedent variable of the intention $(\mathrm{H} 1:$ Exp $\rightarrow \mathrm{IB})$ had significant positive effects. This result implies that the extended TPB has an excellent explanatory ability for the intention of garbage sorting after adding the expectation variable. This approach improves our understanding of how expectation affects the intention to garbage sorting and has crucial theoretical value. The intention to sorting garbage is positively affected when urban residents expect that their actions will eventually significantly improve the environment quality. This finding conforms to that of Kiatkawsin and Han [24] and Tang, Liu and Long [29], who reported evidence that individuals with higher expectation were more likely to form an intention to behave pro-environmentally. This result provides a strategy for boosting residents' intention to garbage sorting and detailed guidance on garbage classification, saving residents' time and energy and reducing confusion about garbage sorting methods in daily life. Moreover, the importance of garbage sorting for improving environmental quality and promoting resource recovery needs to be constantly strengthened. This information increases positive expectations, resulting in the intention to garbage sorting.

Our results showed that three variables in the original TPB model (attitude (H2), subjective norm (H3) and perceived behavioral control (H4)) were positively and significantly associated with the expectation of garbage sorting. The results suggest that urban residents' perceived expectations of garbage sorting are higher when they have favorable attitude toward garbage sorting and experience social pressure to the garbage sorting in daily life. Notably, the path coefficient of D1 (0.316) in the final TPB model was much higher than that of the other three antecedents associated with expectation of garbage sorting (see Table 4). The above results indicate that the level of residents' environmental concern is the primary determinant of the expectation of garbage sorting, and that the total impact of the EC $\rightarrow$ Exp relationship on the expectations is 0.344 (see Table 5). In other words, the higher the environmental concern, the more likely it is that the residents' have a high expectation of garbage sorting. Therefore, in the era of mandatory garbage classification, the government should take measures to enhance the urban residents' environmental concerns to strengthen the synergies between the various measures [79]. The current study suggests a potential strategy for raising the level of the environmental concerns of urban residents. The higher the cognition of urban residents' environmental benefits, the more likely they are to have higher environmental concerns. If the implementation of a policy 
can significantly improve environmental quality, it will significantly enhance the residents' responsiveness to environmental benefits. Thus, the government should carefully analyze the measures of garbage classification through various channels (such as schools, communities and public places), so that the measures do not represent a punishment, which would weaken the positive aspects of the policy.

As an essential antecedent variable of an individual's participation in pro-environmental behavior, the moral norm is often added to TPB models to improve the predictive ability of extended TPB models $[23,25,37,49,67,80]$. Therefore, we attempted to add moral norm to the TPB model and found that this variable indirectly affected expectation of garbage sorting through attitude. This finding verifies the theoretical contribution of the moral norm to the extended TPB model [9]. It is worth noting that the direct influence of the $\mathrm{EB} / \mathrm{EC} \rightarrow \mathrm{MN}$ relationship is significant and positive. This result is in line with the argument by Shi, Fan and Zhao [67] that people who have higher environmental concern are more likely to have higher moral norm. In addition, environmental benefits can also indirectly affect moral norms through environmental concerns; the indirect effect of the $\mathrm{EB} \rightarrow \mathrm{MN}$ relationship was $24.1 \%$ of the total impact. The present study found that the extended TPB that included environmental benefits and concerns as new variables was a useful framework for describing the impact of moral norms and attitude on expectation of garbage sorting. The magnitude of the total effect of $\mathrm{EC} \rightarrow \operatorname{Exp}$ was 1.2 times greater than $\mathrm{SN} \rightarrow$ Exp.

In summary, enhancing urban residents' expectation of garbage sorting could be an alternative guiding principle in follow-up policy supplements. If the government adopts this principle and uses other variables in the TPB model, the intention to garbage sorting can be improved. In addition, the results of this study suggest that the follow-up policy supplements should be improved by considering environmental benefits and concerns. The results showed that environmental benefits and concerns should be taken into account in policy measures to strengthen urban residents' attitude, moral norm, subjective norm and perceived behavioral control.

\subsection{Limitations and Future Research}

Several limitations of this study have to be considered in the future. First, this study used a specific context (i.e., the era of mandatory garbage classification) and expanded the TPB by integration with the NAM and ET. Thus, the sample dataset may not be representative. A replication of this study in different scenarios and with different behaviors will improve the generalization ability of the proposed method and the integrity of the findings. Second, due to the nature of online data collection, the actual behavior of urban residents regarding garbage sorting cannot be tracked. Since the actual behavior is highly variable, we replaced behavior with intention. Finally, an assessment of the implementation results of the mandatory garbage classification policy is critical to ensure effective policy implementation. The assessment results can influence follow-up policies and multi-path interventions regarding the behavior of urban residents' related to garbage sorting.

\section{Conclusions}

This study developed an extended TPB model that integrated the TPB, the NAM and Vroom's ET. We analyzed the influences of social-psychological factors on urban residents intention to garbage sorting in pilot cities in China. The main conclusions were as follows. First, the explanatory ability of the extended TPB for garbage sorting intention was $31.9 \%$. Second, new insights were found and confirmed regarding the relationship between expectation and intention to garbage sorting. The expectation significantly positively affected the intention to garbage sorting. Third, our research highlights the importance of environmental benefits and concerns as antecedents affecting subjective norms, moral norms, perceived behavioral control and expectation by empirically demonstrating that urban residents deriving higher environmental benefits and having greater environmental concerns have higher expectations and intentions to garbage sorting. 
Based on these results, it is suggested that governments and decisionmakers should consider increasing urban residents' environmental benefits and concerns related to garbage sorting to promote their expectation of this activity. The government should gradually implement a legal system for managing garbage to maintain moderate social pressure. Finally, it is necessary to achieve a better understanding of the social-psychological factors affecting urban residents in practical applications and develop a more detailed and scientific approach to guide garbage sorting.

Supplementary Materials: The following are available online at https:/ /www.mdpi.com/article/10 $.3390 /$ su132312985/s1, Table S1. Construct and measurement items.

Author Contributions: Conceptualization, Investigation, Data analysis, Writing—original draft, Writing-review and editing, H.W.; Supervision, Writing—review and editing, H.G.; Methodology, Supervision, Writing—review and editing, C.R.; Supervision, Writing—review and editing, G.L. All authors have read and agreed to the published version of the manuscript.

Funding: This research was funded by National Natural Science Foundation of China (41972166, 41773100), Projects of Anhui Province University Outstanding Youth Talent Support Program (No. gxyq2018224) and Scientific Research Foundation for Outstanding Talents of Huaibei Normal University (No. 03106128).

Institutional Review Board Statement: This questionnaire was anonymous and does not involve personal information collection.

Informed Consent Statement: Informed consent was obtained from all individuals involved in this study.

Data Availability Statement: All the data used for analysis can be obtained from the corresponding author with reasonable requests.

Conflicts of Interest: The authors declare no conflict of interest.

\section{References}

1. Wang, Y.; Shi, Y.; Zhou, J.; Zhao, J.; Maraseni, T.; Qian, G. Implementation effect of municipal solid waste mandatory sorting policy in Shanghai. J. Environ. Manag. 2021, 298, 113512. [CrossRef] [PubMed]

2. Meng, X.; Wen, Z.; Qian, Y. Multi-agent based simulation for household solid waste recycling behavior. Resour. Conserv. Recycl. 2018, 128, 535-545. [CrossRef]

3. Tong, Y.; Liu, J.; Liu, S. China is implementing “Garbage Classification” action. Environ. Pollut. 2019, 259, 113707. [CrossRef] [PubMed]

4. Tai, J.; Zhang, W.; Che, Y.; Feng, D. Municipal solid waste source-separated collection in China: A comparative analysis. Waste Manag. 2011, 31, 1673-1682. [CrossRef] [PubMed]

5. Zhang, H.; Liu, J.; Wen, Z.-G.; Chen, Y.-X. College students' municipal solid waste source separation behavior and its influential factors: A case study in Beijing, China. J. Clean. Prod. 2017, 164, 444-454. [CrossRef]

6. Cudjoe, D.; Yuan, Q.; Han, M.S. An assessment of the influence of awareness of benefits and perceived difficulties on waste sorting intention in Beijing. J. Clean. Prod. 2020, 272, 123084. [CrossRef]

7. Zhang, S.; Hu, D.; Lin, T.; Li, W.; Zhao, R.; Yang, H.; Pei, Y.; Jiang, L. Determinants affecting residents' waste classification intention and behavior: A study based on TPB and A-B-C methodology. J. Environ. Manag. 2021, 290, 112591. [CrossRef]

8. Wang, S.; Wang, J.; Yang, S.; Li, J.; Zhou, K. From intention to behavior: Comprehending residents' waste sorting intention and behavior formation process. Waste Manag. 2020, 113, 41-50. [CrossRef]

9. Zhang, B.; Lai, K.-H.; Wang, B.; Wang, Z. From intention to action: How do personal attitudes, facilities accessibility, and government stimulus matter for household waste sorting? J. Environ. Manag. 2019, 233, 447-458. [CrossRef] [PubMed]

10. Wang, Z.; Dong, X.; Yin, J. Antecedents of urban residents' separate collection intentions for household solid waste and their willingness to pay: Evidence from China. J. Clean. Prod. 2018, 173, 256-264. [CrossRef]

11. Han, H. Travelers' pro-environmental behavior in a green lodging context: Converging value-belief-norm theory and the theory of planned behavior. Tour. Manag. 2015, 47, 164-177. [CrossRef]

12. Gao, L.; Wang, S.; Li, J.; Li, H. Application of the extended theory of planned behavior to understand individual's energy saving behavior in workplaces. Resour. Conserv. Recy. 2017, 127, 107-113. [CrossRef]

13. Cordano, M.; Frieze, I. Pollution reduction preferences of U.S. environmental managers: Applying Ajzen'S theory of planned behavior. Acad. Manag. J. 2000, 43, 627-641. 
14. De Leeuw, A.; Valois, P.; Ajzen, I.; Schmidt, P. Using the theory of planned behavior to identify key beliefs underlying proenvironmental behavior in high-school students: Implications for educational interventions. J. Environ. Psychol. 2015, 42, 128-138. [CrossRef]

15. Xu, X.; Wang, S.; Yu, Y. Consumer's intention to purchase green furniture: Do health consciousness and environmental awareness matter? Sci. Total Environ. 2020, 704, 135275. [CrossRef]

16. Zahedi, S.; Batista-Foguet, J.M.; van Wunnik, L. Exploring the public's willingness to reduce air pollution and greenhouse gas emissions from private road transport in Catalonia. Sci. Total Environ. 2019, 646, 850-861. [CrossRef] [PubMed]

17. Sok, J.; Borges, J.R.; Schmidt, P.; Ajzen, I. Farmer behaviour as reasoned action: A critical review of research with the theory of planned behaviour. J. Agric. Econ. 2021, 72, 388-412. [CrossRef]

18. Fishbein, M.; Ajzen, I. Belief, Attitude, Intention and Behaviour: An Introduction to Theory and Research; Adison-Wesley: Reading, MA, USA, 1975; Volume 27.

19. Ajzen, I. The theory of planned behavior. Organ. Behav. Hum. Decis. Process. 1991, 50, 179-211. [CrossRef]

20. Ajzen, I. From intentions to actions: A theory of planned behavior. In Action-Control: From Cognition to Behaviour; Kuhl, J., Beckmann, J., Eds.; Springer: Berlin, Germany, 1985; pp. 11-39.

21. Morren, M.; Grinstein, A. Explaining environmental behavior across borders: A meta-analysis. J. Environ. Psychol. 2016, 47, 91-106. [CrossRef]

22. Ajzen, I. The theory of planned behavior: Frequently asked questions. Hum. Behav. Emerg. Technol. 2020, 2, 314-324. [CrossRef]

23. Ru, X.; Qin, H.; Wang, S. Young people's behaviour intentions towards reducing PM2.5 in China: Extending the theory of planned behaviour. Resour. Conserv. Recy. 2019, 141, 99-108. [CrossRef]

24. Kiatkawsin, K.; Han, H. Young travelers' intention to behave pro-environmentally: Merging the value-belief-norm theory and the expectancy theory. Tour. Manag. 2017, 59, 76-88. [CrossRef]

25. Yoon, A.; Jeong, D.; Chon, J. The impact of the risk perception of ocean microplastics on tourists' pro-environmental behavior intention. Sci. Total Environ. 2021, 774, 144782. [CrossRef]

26. Ajzen, I. Perceived behavioral control, self-efficacy, locus of control, and the theory of planned behavior1. J. Appl. Soc. Psychol. 2002, 32, 665-683. [CrossRef]

27. Vroom, V. Work and Motivation; Wiley: New York, NY, USA, 1964; Volume 54.

28. Chiang, C.-F.; Jang, S. An expectancy theory model for hotel employee motivation. Int. J. Hosp. Manag. 2008, $27,313-322$. [CrossRef]

29. Tang, H.; Liu, Z.; Long, X. Analyzing the farmers' pro-environmental behavior intention and their rural tourism livelihood in tourist village where its ecological environment is polluted. PLoS ONE 2021, 16, e0247407. [CrossRef] [PubMed]

30. Hsu, C.H.C.; Cai, L.A.; Li, M. Expectation, motivation, and attitude: A tourist behavioral model. J. Travel Res. 2010, 49, 282-296. [CrossRef]

31. Hackman, J.R.; Porter, L.W. Expectancy theory predictions of work effectiveness. Organ. Behav. Hum. Perform. 1968, 3, 417-426. [CrossRef]

32. Lawler, E.E.; Suttle, J.L. Expectancy theory and job behavior. Organ. Behav. Hum. Perform. 1973, 9, 482-503. [CrossRef]

33. Kraft, P.; Rise, J.; Sutton, S.; Røysamb, E. Perceived difficulty in the theory of planned behaviour: Perceived behavioural control or affective attitude? Brit. J. Soc. Psychol. 2005, 44, 479-496. [CrossRef] [PubMed]

34. Wang, Z.; Mao, X.; Zeng, W.; Xie, Y.; Ma, B. Exploring the influencing paths of natives' conservation behavior and policy incentives in protected areas: Evidence from China. Sci. Total Environ. 2020, 744, 140728. [CrossRef] [PubMed]

35. Yee, C.H.; Al-Mulali, U.; Ling, G.M. Intention towards renewable energy investments in Malaysia: Extending theory of planned behaviour. Environ. Sci. Pollut. Res. 2021. [CrossRef]

36. Shalender, K.; Sharma, N. Using extended Theory of Planned Behaviour (TPB) to predict adoption intention of electric vehicles in India. Environ. Dev. Sustain. 2021, 23, 665-681. [CrossRef]

37. Wan, C.; Shen, G.Q.; Choi, S. The place-based approach to recycling intention: Integrating place attachment into the extended theory of planned behavior. Resour. Conserv. Recycl. 2021, 169, 105549. [CrossRef]

38. Sánchez-García, M.; Zouaghi, F.; Lera-López, F.; Faulin, J. An extended behavior model for explaining the willingness to pay to reduce the air pollution in road transportation. J. Clean. Prod. 2021, 314, 128134. [CrossRef]

39. Sánchez, M.; López-Mosquera, N.; Lera-López, F.; Faulin, J. An extended planned behavior model to explain the willingness to pay to reduce noise pollution in road transportation. J. Clean. Prod. 2018, 177, 144-154. [CrossRef]

40. Quintal, V.A.; Lee, J.A.; Soutar, G.N. Risk, uncertainty and the theory of planned behavior: A tourism example. Tour. Manag. 2010, 31, 797-805. [CrossRef]

41. Tama, R.A.Z.; Ying, L.; Yu, M.; Hoque, M.M.; Adnan, K.M.M.; Sarker, S.A. Assessing farmers' intention towards conservation agriculture by using the Extended Theory of Planned Behavior. J. Environ. Manag. 2021, 280, 111654. [CrossRef]

42. Akbari, M.; Fozouni Ardekani, Z.; Pino, G.; Maleksaeidi, H. An extended model of Theory of Planned Behavior to investigate highly-educated Iranian consumers' intentions towards consuming genetically modified foods. J. Clean. Prod. 2019, 227, 784-793. [CrossRef]

43. Schwartz, S.H. Normative influences on altruism. Adv. Exp. Soc. Psychol. 1977, 10, 221-279.

44. Bamberg, S.; Hunecke, M.; Blöbaum, A. Social context, personal norms and the use of public transportation: Two field studies. J. Environ. Psychol. 2007, 27, 190-203. [CrossRef] 
45. Klöckner, C.A. A comprehensive model of the psychology of environmental behaviour-A meta-analysis. Glob. Environ. Chang. 2013, 23, 1028-1038. [CrossRef]

46. Fornara, F.; Pattitoni, P.; Mura, M.; Strazzera, E. Predicting intention to improve household energy efficiency: The role of value-belief-norm theory, normative and informational influence, and specific attitude. J. Environ. Psychol. 2016, 45, 1-10. [CrossRef]

47. Stern, P.C. New environmental theories: Toward a coherent theory of environmentally significant behavior. J. Soc. Issues 2000, 56, 407-424. [CrossRef]

48. Stern, P.; Dietz, T.; Abel, T.; Guagnano, G.; Kalof, L. A value-belief-norm theory of support for social movements: The case of environmentalism. Hum. Ecol. Rev. 1999, 6, 81-97.

49. Chen, M.-F.; Tung, P.-J. Developing an extended Theory of Planned Behavior model to predict consumers' intention to visit green hotels. Int. J. Hosp. Manag. 2014, 36, 221-230. [CrossRef]

50. Ng, P.Y.; Phung, P.T. Public transportation in Hanoi: Applying an integrative model of behavioral intention. Case. Stud. Transp. Policy 2021, 9, 395-404. [CrossRef]

51. Choi, S.; Kim, Y. Antecedents of green purchase behavior: An examination of collectivism, environmental concern, and PCE. Adv. Consum. Res. 2005, 32, 592-599.

52. Wan, C.; Shen, G.Q.; Choi, S. Experiential and instrumental attitudes: Interaction effect of attitude and subjective norm on recycling intention. J. Environ. Psychol. 2017, 50, 69-79. [CrossRef]

53. Dunlap, R.E.; Van Liere, K.D.; Mertig, A.G.; Jones, R.E. New trends in measuring environmental attitudes: Measuring endorsement of the new ecological paradigm: A revised NEP scale. J. Soc. Issues 2000, 56, 425-442. [CrossRef]

54. Van Riper, C.J.; Kyle, G.T. Understanding the internal processes of behavioral engagement in a national park: A latent variable path analysis of the value-belief-norm theory. J. Environ. Psychol. 2014, 38, 288-297. [CrossRef]

55. Karpudewan, M. The relationships between values, belief, personal norms, and climate conserving behaviors of Malaysian primary school students. J. Clean. Prod. 2019, 237, 117748. [CrossRef]

56. Razali, F.; Daud, D.; Weng-Wai, C.; Anthony Jiram, W.R. Waste separation at source behaviour among Malaysian households: The theory of planned behaviour with moral norm. J. Clean. Prod. 2020, 271, 122025. [CrossRef]

57. López-Mosquera, N.; Sánchez, M. Theory of Planned Behavior and the Value-Belief-Norm Theory explaining willingness to pay for a suburban park. J. Environ. Manag. 2012, 113, 251-262. [CrossRef]

58. Karimi, S.; Liobikienè, G.; Saadi, H.; Sepahvand, F. The influence of media usage on iranian students' pro-environmental behaviors: An application of the extended theory of planned behavior. Sustainability 2021, 13, 8299. [CrossRef]

59. Yadav, R.; Pathak, G.S. Young consumers' intention towards buying green products in a developing nation: Extending the theory of planned behavior. J. Clean. Prod. 2016, 135, 732-739. [CrossRef]

60. Cheah, I.; Phau, I. Attitudes towards environmentally friendly products: The influence of ecoliteracy, interpersonal influence and value orientation. Mark. Intell. Plan. 2011, 29, 452-472. [CrossRef]

61. Podsakoff, P.; MacKenzie, S.; Podsakoff, N. Recommendations for creating better concept definitions in the organizational, behavioral, and social sciences. Organ. Res. Methods 2016, 19, 159-203. [CrossRef]

62. Podsakoff, P.M.; MacKenzie, S.B.; Lee, J.Y.; Podsakoff, N.P. Common method biases in behavioral research: A critical review of the literature and recommended remedies. J. Appl. Psychol. 2003, 88, 879-903. [CrossRef]

63. Becker-Leifhold, C.V. The role of values in collaborative fashion consumption-A critical investigation through the lenses of the theory of planned behavior. J. Clean. Prod. 2018, 199, 781-791. [CrossRef]

64. Nunkoo, R.; Ramkissoon, H.; Gursoy, D. Use of structural equation modeling in tourism research past, present, and future. J. Travel. Res. 2013, 52, 759-771. [CrossRef]

65. Nunkoo, R.; Ramkissoon, H. Structural equation modelling and regression analysis in tourism research. Curr. Issues Tour. 2012, 15, 777-802. [CrossRef]

66. Anderson, J.C.; Gerbing, W. Structural equation modeling in practice: A review and recommended two-step approach. Psychol. Bull. 1988, 27, 5-24. [CrossRef]

67. Shi, H.; Fan, J.; Zhao, D. Predicting household PM2.5-reduction behavior in Chinese urban areas: An integrative model of Theory of Planned Behavior and Norm Activation Theory. J. Clean. Prod. 2017, 145, 64-73. [CrossRef]

68. Wang, S.; Ji, C.; He, H.; Zhang, Z.; Zhang, L. Tourists' waste reduction behavioral intentions at tourist destinations: An integrative research framework. Sustain. Prod. Consump. 2021, 25, 540-550. [CrossRef]

69. Fornell, C.; Larcker, D. Evaluating structural equation models with unobservable variables and measurement error. J. Mark. Res. 1981, 24, 337-346. [CrossRef]

70. Hair, J.F., Jr.; Anderson, R.E.; Babin, B.J.; Black, W.C. Multivariate Data Analysis: A Global Perspective, 7th ed.; Pearson Education: Upper Saddle River, NJ, USA, 2010.

71. Gkargkavouzi, A.; Halkos, G.; Matsiori, S. Environmental behavior in a private-sphere context: Integrating theories of planned behavior and value belief norm, self-identity and habit. Resour. Conserv. Recycl. 2019, 148, 145-156. [CrossRef]

72. Hair, J.; Black, W.; Babin, B.; Anderson, R. Multivariate Data Analysis; Prentice Hall: New York, NY, USA, 2009.

73. Cheung, G.; Rensvold, R. Evaluating goodness-of-fit indexes for testing measurement invariance. Struct. Equ. Model. 2002, 9 , 233-255. [CrossRef]

74. MacKinnon, D.; Fairchild, A.; Fritz, M. Mediation analysis. Annu. Rev. Psychol. 2007, 58, 593-614. [CrossRef] [PubMed] 
75. Williams, J.; MacKinnon, D.P. Resampling and distribution of the product methods for testing indirect effects in complex models. Struct. Equ. Model. 2008, 15, 23-51. [CrossRef]

76. Bollen, K.; Stine, R. Direct and indirect effects: Classical and bootstrap estimates of variability. Sociol. Methodol. 1990, 20, 115. [CrossRef]

77. Stone, C.; Sobel, M. The robustness of estimates of total indirect effects in covariance structure models estimated by maximum. Psychometrika 1990, 55, 337-352. [CrossRef]

78. Bamberg, S.; Ajzen, I.; Schmidt, P. Choice of travel mode in the theory of planned behavior: The roles of past behavior, habit, and reasoned action. Basic Appl. Soc. Psychol. 2003, 25, 175-187. [CrossRef]

79. Kuang, Y.; Lin, B. Public participation and city sustainability: Evidence from Urban Garbage Classification in China. Sustain. Cities. Soc. 2021, 67, 102741. [CrossRef]

80. López-Mosquera, N. Gender differences, theory of planned behavior and willingness to pay. J. Environ. Psychol. 2016, 45, 165-175. [CrossRef] 